\title{
Protoblock - A biological standard for formalin fixed samples
}

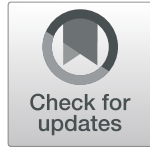

Yensi Flores Bueso ${ }^{1,2,3}$, Sidney P. Walker ${ }^{1,2,3,4}$, Glenn Hogan ${ }^{1,2}$, Marcus J. Claesson ${ }^{3,4}$ and Mark Tangney ${ }^{1,2,3^{*}}$ (D)

\begin{abstract}
Background: Formalin-fixed, paraffin-embedded (FFPE) tissue is the gold standard in pathology tissue storage, representing the largest collections of patient material. Their reliable use for DNA analyses could open a trove of potential samples for research and are currently being recognised as a viable source material for bacterial analysis. There are several key features which limit bacterial-related data generation from this material: (i) DNA damage inherent to the fixing process, (ii) low bacterial biomass that increases the vulnerability to contamination and exacerbates the host DNA effects and (iii) lack of suitable DNA extraction methods, leading to data bias. The development and systematic use of reliable standards is a key priority for microbiome research. More than perhaps any other sample type, FFPE material urgently requires the development of standards to ensure the validity of results and to promote reproducibility.

Results: To address these limitations and concerns, we have developed the Protoblock as a biological standard for FFPE tissue-based research and method optimisation. This is a novel system designed to generate bespoke mock FFPE 'blocks' with a cell content that is user-defined and which undergoes the same treatment conditions as clinical FFPE tissues. The 'Protoblock' features a mix of formalin-fixed cells, of known number, embedded in an agar matrix which is solidified to form a defined shape that is paraffin embedded.

The contents of various Protoblocks populated with mammalian and bacterial cells were verified by microscopy. The quantity and condition of DNA purified from blocks was evaluated by qPCR, 16S rRNA gene amplicon sequencing and whole genome sequencing. These analyses validated the capability of the Protoblock system to determine the extent to which each of the three stated confounding features impacts on eventual analysis of cellular DNA present in FFPE samples.

Conclusion: The Protoblock provides a representation of biological material after FFPE treatment. Use of this standard will greatly assist the stratification of biological variations detected into those legitimately resulting from experimental conditions, and those that are artefacts of the processed nature of the samples, thus enabling users to relate the outputs of laboratory analyses to reality.
\end{abstract}

Keywords: FFPE, Microbiome, PCR, DNA, Bacteria, Microscopy

\footnotetext{
* Correspondence: m.tangney@ucc.ie

'CancerResearch@UCC, University College Cork, Cork, Ireland

${ }^{2}$ SynBioCentre, University College Cork, Cork, Ireland

Full list of author information is available at the end of the article
}

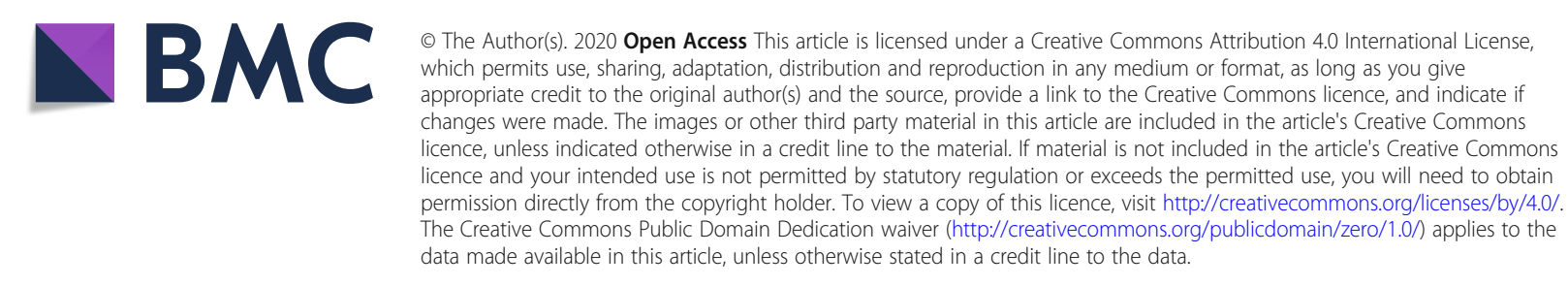




\section{Background}

Increased sequencing capabilities have driven progress in the study of the human microbiome [1-3], and distinct microbial profiles have been reported in body sites previously thought of as sterile (although many are potentially influenced by environmental contamination) [4-9]. These discoveries have steered a higher demand for patient samples, availability of which can be highly constrained when sampling from body sites that involve invasive sampling procedures $[10,11]$.

In an attempt to satisfy this demand, the use of formalinfixed paraffin-embedded tissue (FFPE) has been explored for microbiome research [12-19]. FFPE tissue is the gold standard for pathology tissue storage and thus represents the largest collection of available patient material [20-22]. The availability of this material has been vital for progress in human genomics, and numerous sequencing workflows have been designed to enable use of, or are based upon, these samples [23-28]. The use of FFPE tissue for microbiome research could open access to large sample cohorts (guaranteeing statistical power), accompanied by a clear clinical history and histology reports. However, FFPE samples carry several limitations and considerations must be taken into account before their reliable use in microbiome research. Investigations into the quality of DNA from human FFPE samples have revealed that factors in the processing and storage (e.g. length of exposure to formalin, $\mathrm{pH}$ of formalin and sample storage time) negatively impact the integrity of nucleic acids and the efficacy of their downstream analyses $[29,30]$. Relevant to microbiome research, unique factors to consider in quality control of FFPE samples are:

1. Low biomass renders samples extremely susceptible to the high burden of contaminants to which they are exposed during the non-sterile FFPE processing [31]. Additionally, it aggravates the influence of host DNA, rendering samples ineffective for whole genome sequencing (WGS) and introducing PCR bias to $16 \mathrm{~S}$ rRNA gene amplicon sequencing [32].

2. FFPE causes DNA damage, in the form of crosslinks, DNA fragmentation and sequence alterations [33]. In this context, 16S rRNA gene amplicon sequencing (V3-V4) necessitates DNA fragments with a length of $460 \mathrm{bp}$ and sequence alterations may lead to false speciation events.

3. No sample prep methods available for microbiome study of this sample type. FFPE microbiome studies to date have utilised approaches designed for FFPE human samples, which are suboptimal for this aim [34].

In order for the potential value of increased usage of FFPE samples for metataxonomics/metagenomics to be realised, the necessary workflows, protocols and quality control standards need to be in place [25, 3537]. Among these, the development and systematic use of biological standards have been recently highlighted as a key priority for microbiome research [38-41]. Given the multiple variables (FFPE processing, storage and DNA isolation process) that directly influence the quantity and quality of DNA recovered from FFPE samples, more than perhaps any other sample type, FFPE tissue urgently requires the development of standards to ensure the validity and reproducibility of results.

A model that serves as a standard for metataxonomic and metagenomic analysis of FFPE samples requires: (1) a defined bacterial and host cell load, (2) exposure to the same treatment as FFPE specimens (fixation and dehydration), (3) a format that resembles FFPE blocks-enabling the same treatment as the source material (sectioning, deparaffinisation). Here presented is the Protoblock, to serve as a biological standard for FFPE samples. The Protoblock is a cell matrix, which can be populated with cell types and numbers as desired, such as to resemble those of the FFPE tissue specimens. It can be integrated in the workflow either at the FFPE processing stage for prospective studies or at the sample prep stage for retrospective studies, allowing the assessment of either workflows, highlighting caveats that must be considered when analysing the sequencing results.

This study describes: (1) the procedures to make the Protoblock and its validation by microscopy and (2) validation of their value as a standard for $16 \mathrm{~S}$ rRNA gene amplicon sequencing and WGS.

\section{Results \\ Protoblock generation and validation Making the Protoblock}

The Protoblock is generated by embedding a known number of fixed cells in an agar matrix that is poured into a mould that renders a defined uniform shape, in this example, a disk. Once the agar solidifies, the blocks are processed as per routine FFPE processing protocols for dehydrating and paraffin embedding and verified by microscopy, see Fig. 1a for procedures used to prepare the Protoblock.

To achieve the desired cell numbers, formalin-fixed cell suspensions were counted with FACS (bacteria) or NucleoCounter (4T1) and the volume of the cell suspensions normalised to cell contents (Fig. 2a). The Protoblock radius, height and volume were measured after dehydration. Average measurements for Protoblocks presented here were $4.99 \pm 0.15 \mathrm{~mm}, 3.57 \pm$ $0.24 \mathrm{~mm}$ and $245.2 \pm 14.2 \mu \mathrm{l}$, respectively. A slide's estimated cell population was calculated by multiplying the cell content per microliter of block by the volume 

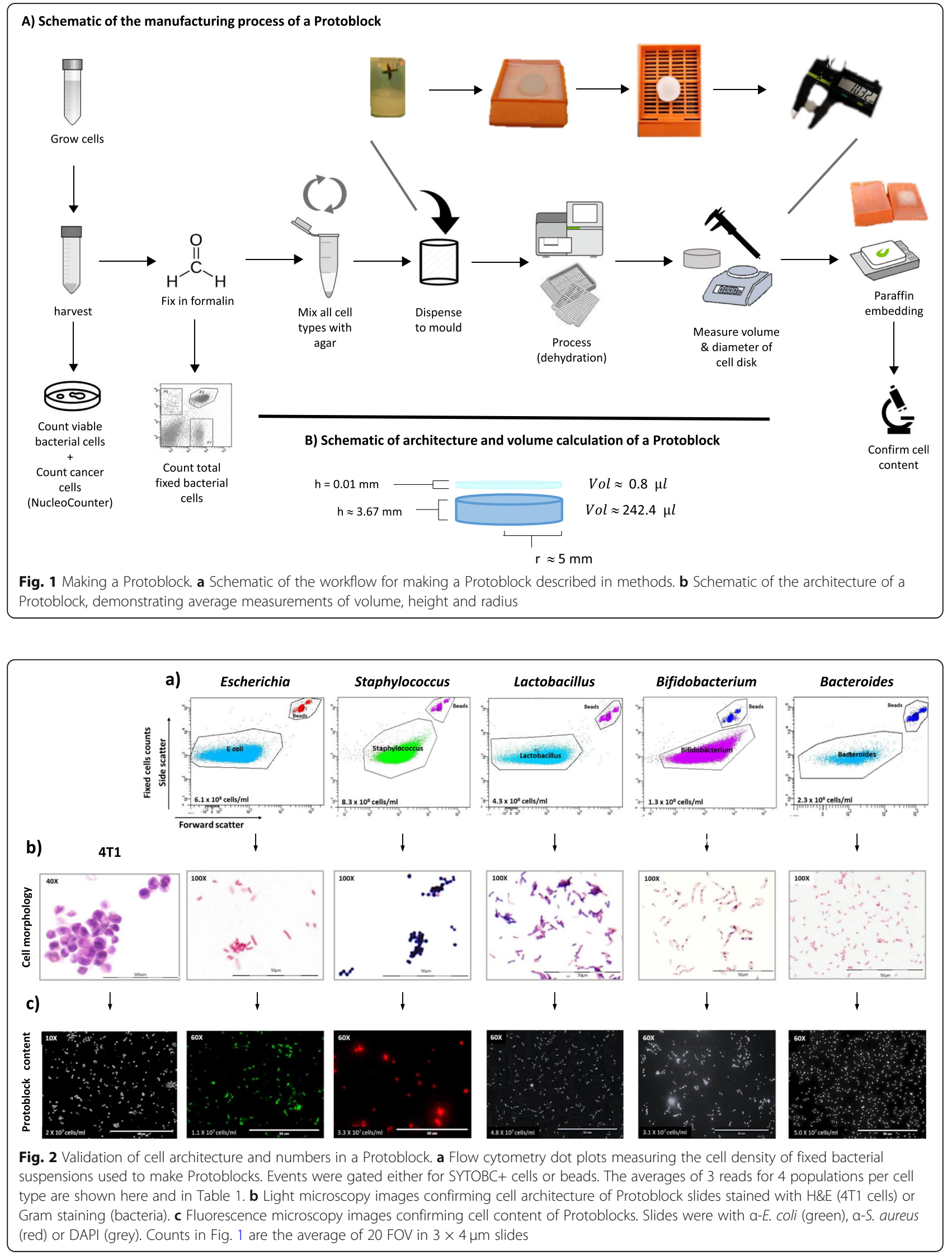
of a $20-\mu \mathrm{m}$ slide $(\bar{x}=1.57 \mu \mathrm{l}, \sigma=0.098 \mu \mathrm{l})$ or $4-\mu \mathrm{m}$ slide $(\bar{x}=0.39 \mu \mathrm{l}, \sigma=0.02 \mu \mathrm{l})$, see Fig. $1 \mathrm{~b}$.

\section{Protoblock validation}

Protoblocks were populated with cell types and cell loads that provided the best resolution for each experimental aim. Comparable ratios of a mix of 5 bacterial strains and 4T1 cells (in the same order of magnitude $\cong 1 \times 10^{7}$ ) were aimed for. Estimated cell content was confirmed by immunofluorescence microscopy in blocks containing individual cell types (Fig. 2c) and mixed cell content (sFigure 1). Cell wall/membrane integrity was assessed by Gram (bacteria) or haematoxylin \& eosin (H\&E) staining (4T1 cells), see Fig. 2b. The calculated and confirmed contents for each Protoblock are specified in Fig. 3 and sTable 1.
Protoblock as a standard for assessing and optimising $16 \mathrm{~S}$ amplicon sequencing and WGS workflows of FFPE samples

\section{A. Assessing the efficacy of currently used methods for purifying bacterial FFPE DNA}

Total DNA was extracted from Protoblocks fixed in formalin for 24 or $48 \mathrm{~h}(10 \times 15 \mu \mathrm{m}$ slides $)$ using the 'gold standard' DNA purification method for FFPE samples used in previous FFPE 16S rRNA amplicon gene sequencing studies (QIAGEN FFPE DNA kit). Recovery was determined via qPCR of strain specific $\cong 460$-bp DNA fragments (length relevant for $16 \mathrm{~S}$ rRNA amplicon gene sequencing). As seen in Fig. 3a (i), FFPE-treated samples had at least a 10-fold reduction in the amount of amplifiable DNA, shown to be statistically significant ( $p<$ 0.001). Although similar amounts of DNA were purified from the samples (Fig. 3c), the PCR readability of DNA

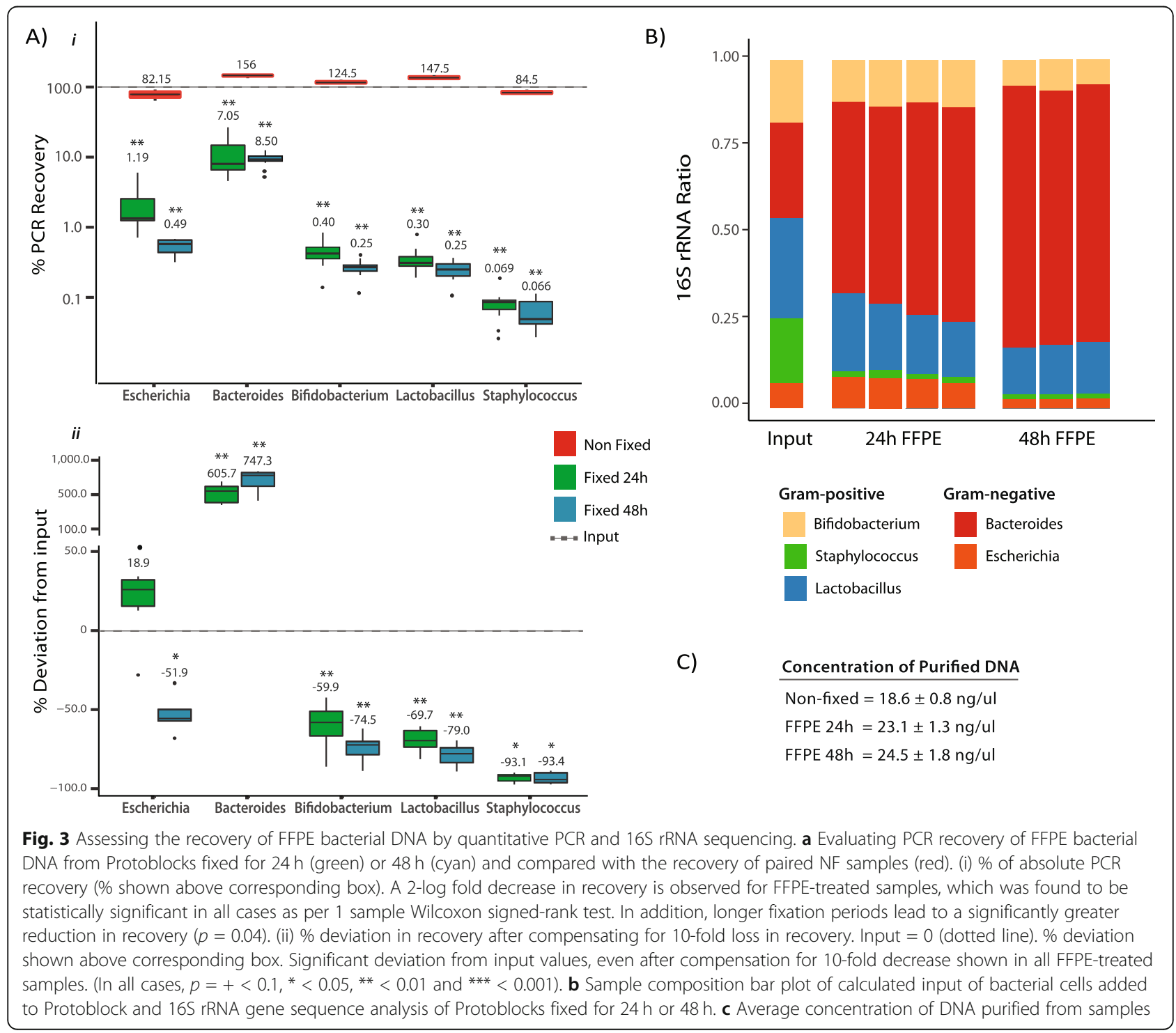


is reduced by FFPE treatment, which is aggravated with increasing fixation time. Furthermore, after compensating for the 2-log fold loss of readable DNA, statistically significant under- and over-representation of all 5 genera present was evident, with a clear bias towards Gramnegative (G-) bacteria (Bacteroides and Escherichia). This was more evident for Bacteroides and Staphylococcus, which were over- and under-represented by $605 \%$ and $-93.1 \%$ respectively (Fig. 3a (ii)). This effect was exacerbated by longer fixation periods. Lysis bias was confirmed with 16S rRNA gene amplicon sequencing (Fig. 3b). Altogether, these data indicate that a bacterial lysis mechanism must be incorporated in the workflow for processing of FFPE samples (this is not included in the QIAGEN kit, optimised for human DNA purification) and that for bacterial FFPE DNA, the baseline recovery of 460-bp fragments is $\leq 2$-log the input. The results from these tests in Protoblocks were corroborated by FFPE murine tumour models as shown in sFigure 2.

\section{B. Assessing the sources of bias}

Next, it was examined whether Protoblocks prove useful for investigating aspects that can introduce bias to a PCR or a sequencing run and for exploring strategies that reduce it.

Membrane/cell wall disruption This was investigated using a mix of lytic enzymes (Metapolyzyme), avoiding bead beating as it is known to fragment DNA. Metapolyzyme effect was evaluated by qPCR in FFPE blocks fixed for $24 \mathrm{~h}$ loaded with Escherichia, Staphylococcus and Bifidobacterium (Fig. 4a (ii)). A marked increase in DNA recovery is evident for all three bacterial strains, indicating that Metapolyzyme lyses both G+ and G- FFPE bacteria. The effect of Metapolyzyme was more pronounced in Staphylococcus, where treatment increased its recovery by $110 \times(p<0.001)$, followed by an $18 \times(p<0.001)$ increase for Bifidobacterium and a $2.6 \times(p<0.001)$ increase for Escherichia (Fig. 4a (i)), altogether bringing all strains to the maximum recovery $\left(1 \times 10^{6}\right)$, considering the log decrease of FFPE samples. This indicates that a sample lysis step like that exemplified here, must be introduced into the sample prep to guarantee a uniform cross-taxa lysis.

Bias introduced by host DNA To evaluate host DNArelated bias independently from bacterial lysis bias, this was first assessed using paired Protoblocks fixed for $48 \mathrm{~h}$ loaded with G- Escherichia and Bacteroides with (4T1+) or without (4T1-) mammalian cells (Fig. 4b (ii)). Samples were processed maintaining equal ratios of bacterial input. Average DNA concentrations after purification are shown in Fig. 4b. PCR reactions were loaded with $10^{6}$ cells. As seen in Fig. 4b (i), despite the low 4T1 cell to bacteria ratio, 4T1 - reactions had on average a $2 \times$ higher bacterial DNA recovery. The same effect was observed later for the $\mathrm{G}+$ Staphylococcus. This is not surprising, given the size of mammalian genomes. Eighty-nine percent of 4T1+ total purified DNA corresponded to mammalian DNA. It is likely that with increased host DNA ratios, this effect would become more pronounced.

Testing strategies for host DNA depletion This was tested in Protoblocks loaded with equal ratios of Escherichia, Staphylococcus and 4T1 cells. Contents of Protoblocks were exposed to known mammalian cell permeabilising solutions (Triton-X, Saponin or Molysis CM solution) and treated with Turbo DNAse [42]. As shown in Fig. 4c, all tested host depletion (HD) strategies significantly reduced the recovery of $4 \mathrm{~T} 1$ DNA. From these, only Saponin did not significantly affect the recovery of $\mathrm{G}-$ Escherichia. All treatments tested increased the recovery of G+Staphylococcus, but only Triton-X did so significantly.

\section{Evaluating DNA damage in terms of fragmentation}

DNA fragmentation DNA integrity was investigated with a fragment analyser by comparing DNA purified from matched NF and Protoblocks (FFPE) samples containing either a mix of non-fixed (NF) bacteria (ratios as sTable 1) or Escherichia only. As seen in Fig. 5a, DNA fragments from NF Escherichia $(\bar{x}=27,102 \mathrm{bp}, \% \mathrm{CV}=$ $65.84)$ or the bacterial mix $(\bar{x}=31,100 \mathrm{bp}, \% \mathrm{CV}=59.19)$ were highly integral (no fragmentation), with a Genomic Quality Number $(\mathrm{GQN})>6.6$, and no significant difference was observed between sample type. On the other hand, DNA fragments from Protoblocks loaded with Escherichia $(\bar{x}=143 \mathrm{bp}, \% \mathrm{CV}=41.93)$ or a bacteria mix $(\bar{x}=110 \mathrm{bp}, \% \mathrm{CV}=53.62)$ were highly fragmented with a GQN $=0.1$ in both sample types. These results were in agreement with FFPE tissue DNA (sFigure 2). These results are comparable with those found in human FFPE samples, where GQN between 0.75 and 2.5 are considered high-quality FFPE DNA and GQN $\leq 0.3$ are low and not recommended for sequencing [43].

Assessment of PCR readable bacterial FFPE DNA Since DNA fragmentation of FFPE bacteria was observed to be equal across taxa investigated here (Fig. 5a), the effect of fragmentation on PCR recovery was investigated with Protoblocks loaded with $10^{8}, 10^{6}$ and $10^{4}$ Escherichia cells, as confirmed with Gram staining (Fig. 5a (iii)). Quantitative PCR reactions loaded with $10^{7}(61.2 \pm 5.2$ ng), $10^{5}(0.8 \pm 0.21 \mathrm{ng})$ or $10^{3}(\sim 0.02 \mathrm{ng})$ bacterial cells were tested for the recovery of a 200-bp (recommended for FFPE) [44, 45] or 460-bp DNA fragment (required for V3-V4 16S rRNA sequencing). This was compared with the recovery of a 460-bp fragment from paired NF (non- 


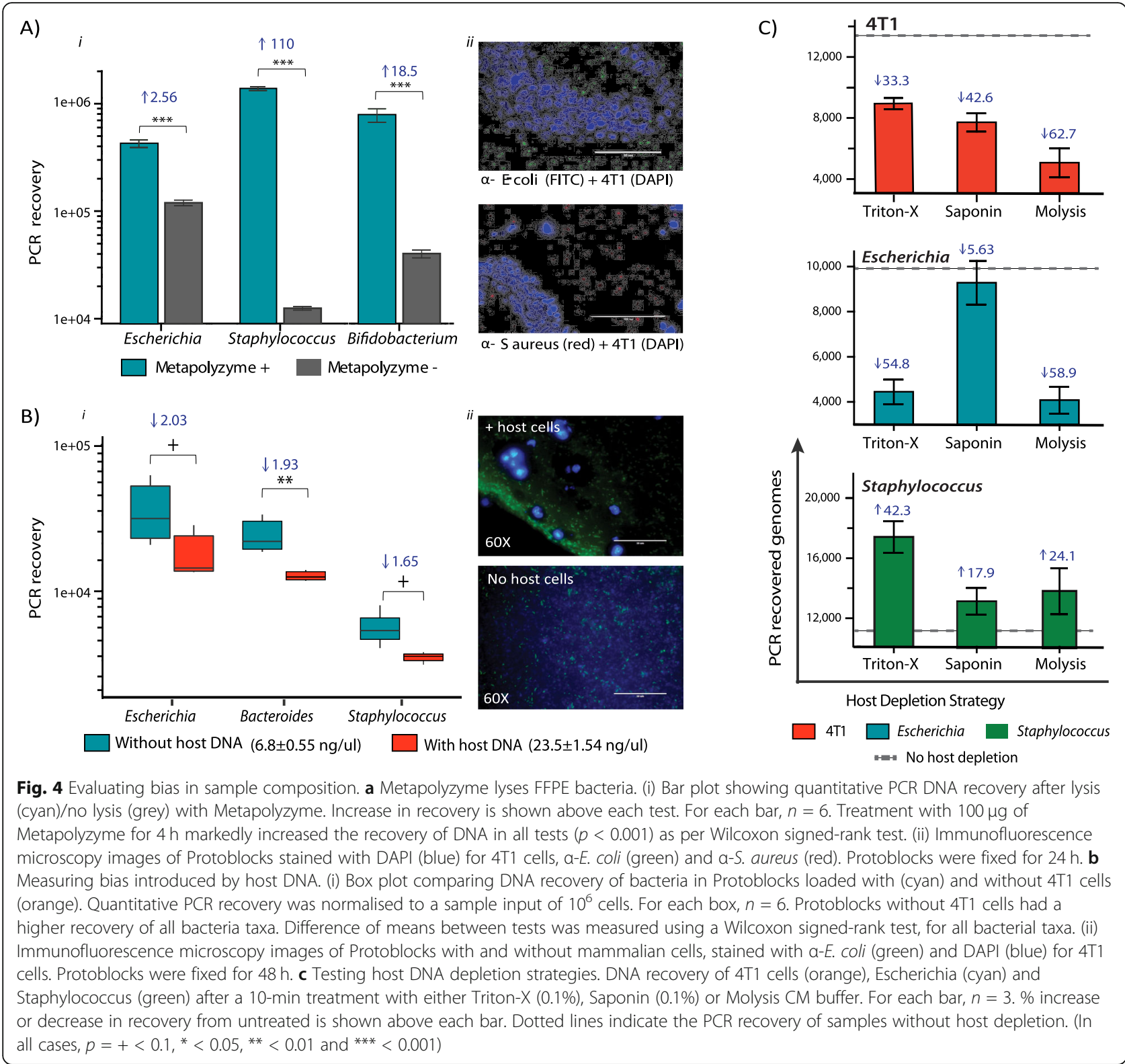

fixed) samples (Fig. 5a (i)). While comparable DNA quantities of paired FFPE/NF samples were loaded into the PCR reactions, a significant $(>1-\log )$ reduction was observed in the quantity of DNA recovered from Protoblock samples $(p<0.001)$. A further decline in recovery $(3-8 \times)$ was evident when targeting longer (460 bp) DNA fragments (Fig. 5a (ii)), a trend that held true across all groups, which varied in terms of quantity of bacteria loaded, thus indicating that DNA fragmentation has a significant effect in the PCR recovery of bacterial DNA $(p<0.001)$.

\section{$D$. Evaluating damage in the sequence quality of bacterial FFPE DNA.}

This was assessed in a Protoblock model populated with E. coli K-12. Purified DNA was normalised to $10^{6}$ genome copies. High-resolution melt (HRM) analysis was performed in 3 contiguous DNA fragments (length $\cong 100 \mathrm{bp}$ ) that make up a region of the InsH1 gene (see Fig. 6a (ii)). To determine the presence of any sequence aberrations in Protoblock FFPE DNA, their melting temperature $(\mathrm{Tm})$ was compared with that of NF DNA and the differences measured. Figure 6a (ii) shows the final $\mathrm{Tm}$ for each fragment investigated. Tm shifts with variable levels of significance were observed in all fragments. This is indicative of a change in the underlying DNA sequence, as would be expected in a clinical FFPE sample. To confirm these results, DNA purified from Protoblocks loaded with Escherichia and Staphylococcus and their paired NF samples were analysed by WGS. Findings from the DNA melting temperature analysis 


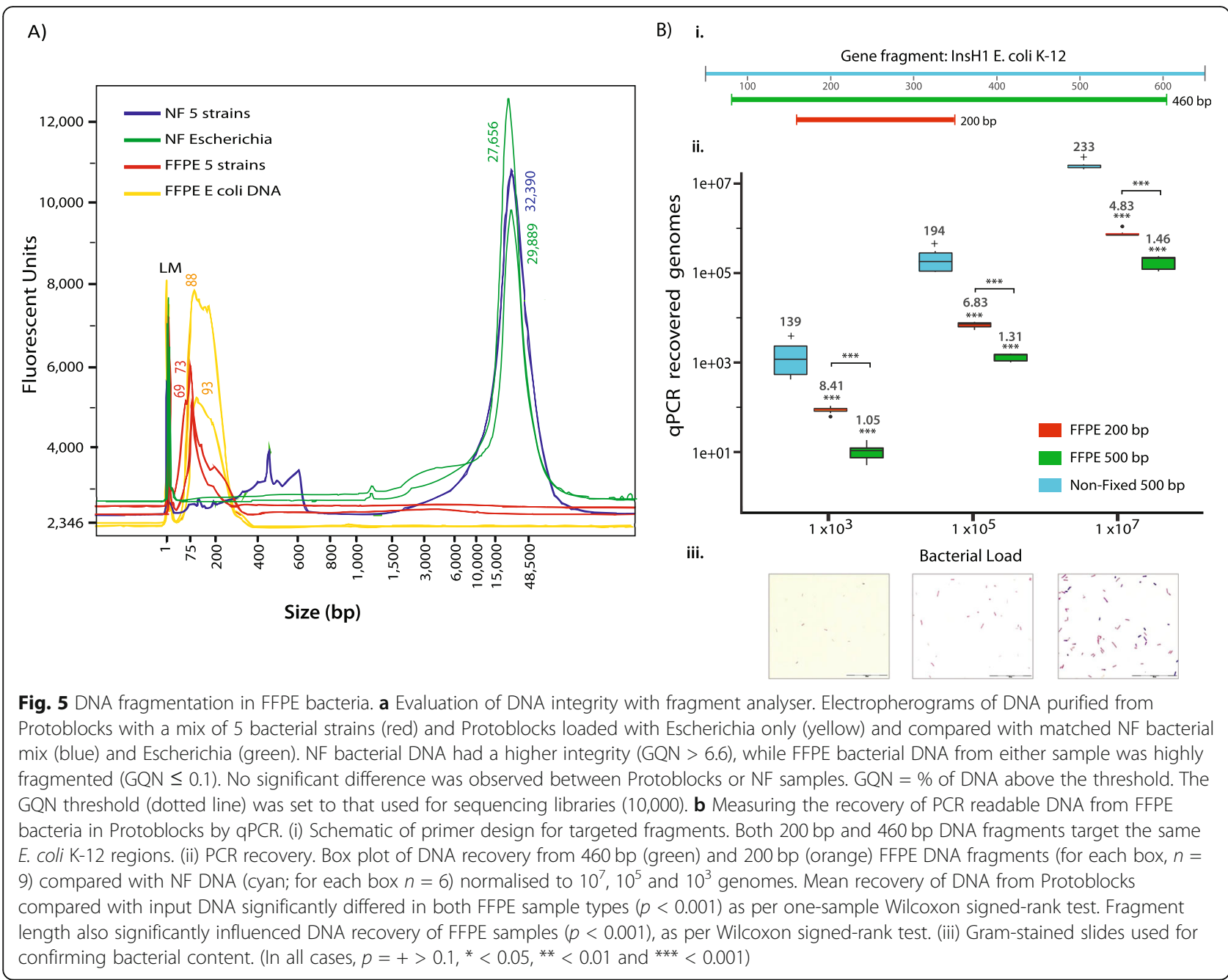

correlated with the results of WGS. For both bacterial strains, a higher number of sequence artefacts (chimeras and SNPs) were found in FFPE samples, when compared with their NF reference (see Fig. 6b).

\section{E. Characterising common contaminants in the FFPE and $16 S$ rRNA gene amplicon sequencing workflow}

The Protoblock is susceptible to contamination in a similar way to clinical FFPE samples. The priority of the fixing process is to preserve the tissue for later histological analysis, not to prepare a sample suitable for a high-throughput bacterial sequencing. In this instance, contamination was detected as shown by the number of reads in the negative controls (Fig. 7). It is unlikely to have had a significant effect on the overall biological signal in this instance, given that the bacterial reads detected, and their taxonomic classifications, differ completely from those of the Protoblocks analysed. It must be stated that the level of bacterial biomass loaded into the Protoblocks is orders of magnitude higher than what can be expected in a clinical FFPE sample, and as such the level of contamination present in the negative control samples poses a significant risk to the accuracy of any sequence-based analysis of clinically collected FFPE samples,

\section{Discussion}

FFPE tissue specimens are an invaluable resource that has driven research in human cancer genomics, where numerous workflows have been developed for these samples. Over a decade of study has revealed that FFPE DNA damage is influenced by many factors during processing and storage. This results in a high inter-sample variability in the degree of DNA damage, with some samples being unsuitable for sequencing analysis [46]. To address this, the development of a robust quality control (QC) system has been crucial in directing workflows maximising the recovery, while guaranteeing the fidelity of analysis outputs. Most notable among these are the analysis of DNA fragment length (fragment analyser) and PCR readability of DNA in a sample (Infinium FFPE QC, Illumina). 


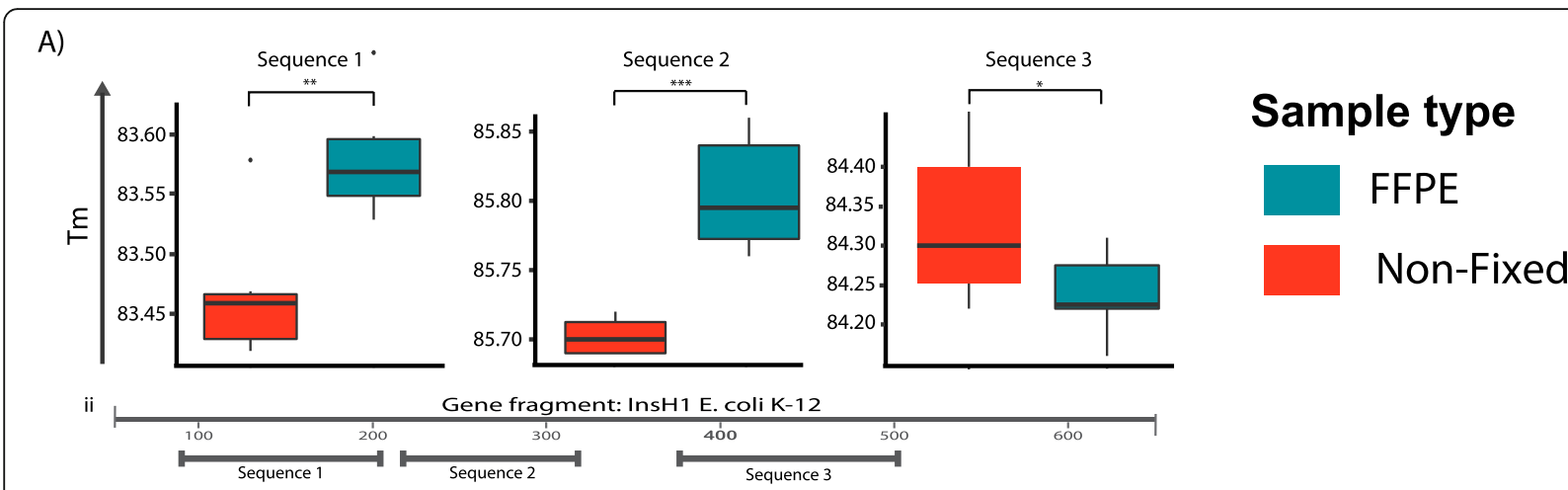

B)

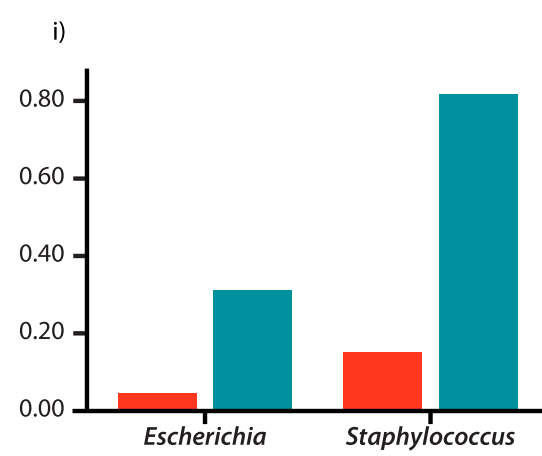

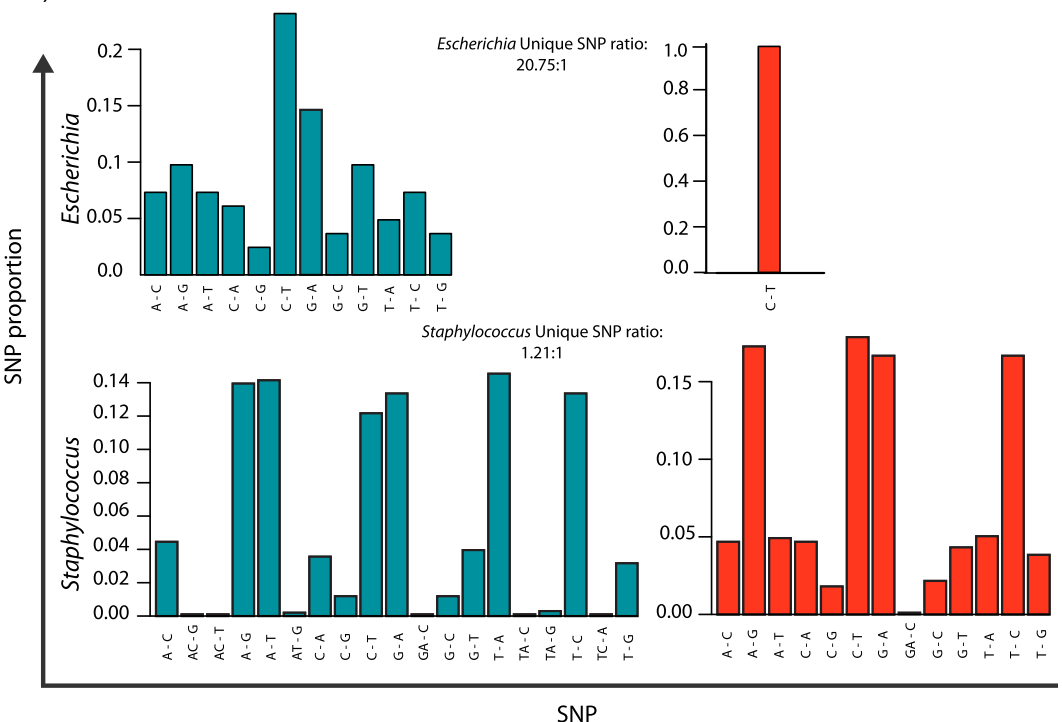

Fig. 6 Evaluating sequence quality of bacterial FFPE DNA. a Evaluation of DNA sequence aberrations by high-resolution-melt analysis. (i) Box plots of normalised DNA quantities from Protoblock FFPE Escherichia (cyan) and NF Escherichia (orange). Significant shifts in the melting temperatures in 2 of the 3 sequences were observed as per Wilcoxon signed-rank test, with temperature shifts that were on average $0.1-0.5^{\circ} \mathrm{C}$ apart from NF counterparts. (ii) Schematic of sequences used for HRM analysis: 3 DNA fragments with an average length of 100 bp were analysed. For each test and each sample type, $n=6$. $\mathbf{b}$ Confirmation of sequence alteration by WGS. DNA from Protoblocks loaded with Escherichia and Staphylococcus and their NF paired reference was analysed by whole genome sequencing to determine chimeric reads and single-nucleotide polymorphisms (SNP) against the reference genome E. coli K12 MG1655 and S. aureus Newman. Here, the SNP are plotted on the $x$-axis and the rate of occurrence on the $y$-axis. Variant calling and level of coverage are measured using SAMTOOLS/BCFTOOLS. (i) Chimeric reads per layer of coverage. (ii) Distribution of SNPs found per bacterial strain

Likewise, before any reliable and reproducible use of FFPE samples for microbiome analysis can be performed, a robust QC system must be developed and systematically implemented. The Protoblock presented here represents a highly relevant starting point. This method is advantageous in that the cell populations and fixation strategies can be adapted to meet the requirements for sample type and sample prep/sequencing workflow to inform on their effects on analysis outputs [47]. Ideally, a mildly fixed version of the Protoblock (bacteria and cells embedded in agar) would be developed in a standardised manner in specialist facilities. These could be used prospectively by researchers/clinicians so that FFPE processing is in line with the methods applied in their hospital/clinic/lab and performed at the same time tissue samples are processed. However, this method could also be adapted by researchers with specialised needs. In this case, commercial standards compatible with the Protoblock or FFPE workflow would highly facilitate the inhouse development and at the same time guarantee sample accuracy and reproducibility.

It has been shown here that the Protoblock is a representative FFPE model, since its contents are exposed to the same processing as FFPE experimental samples and has the same degree of DNA damage (fragmentation, PCR recovery and sequence alteration) as clinical FFPE 


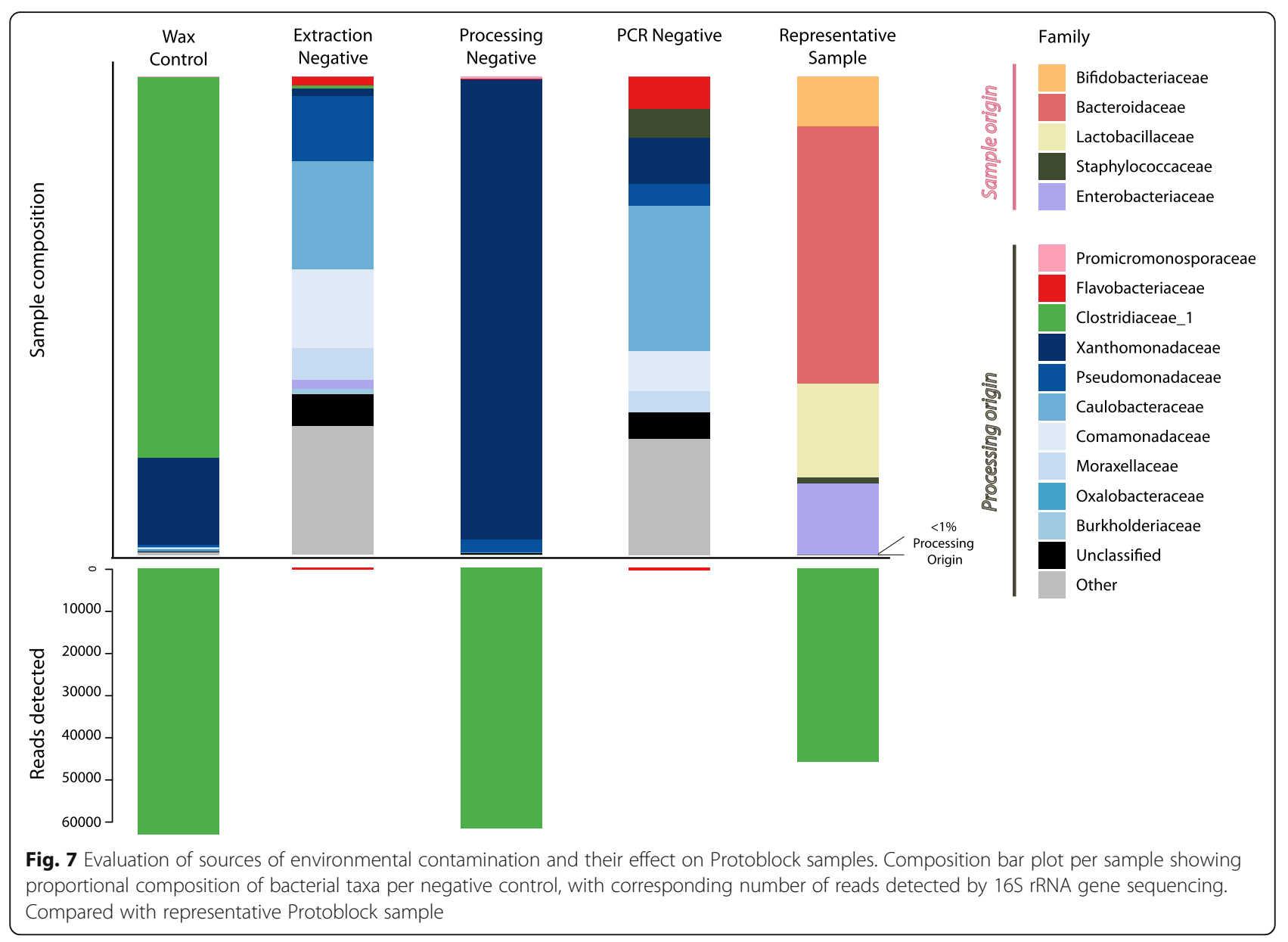

tissue samples. Moreover, the degree of DNA damage in the Protoblocks can be modulated by changing the fixation time. This advantage can be exploited to develop a system similar to Infinium FFPE QC (Illumina), where a sample with a good DNA quality score serves as a standard and $\mathrm{Cq}$ deviations from this inform on the suitability of samples for sequencing analysis. The Protoblock can also serve as a quantitative standard to determine cycle number at which tested FFPE samples will have detectable levels of $16 \mathrm{~S}$ rRNA gene sequences, if any.

The Protoblock was also proven effective as a control for optimising the sample prep workflow for microbiome analysis. Here, it informed on expected sources of bias, such as that introduced by host DNA, while at the same time allowing for the assessment of host DNA depletion strategies. The Protoblock also educated on bias introduced by the bacterial lysis strategy included in the sample prep used (an impact that has been well documented) $[48,49]$. From the results shown here, it is clear the QIAGEN FFPE DNA sample prep is unsuitable for microbiome analysis, since it is strongly biased towards Gram-negative bacteria. However, due to the lack of a standardised sample prep methods for microbiome analysis specifically designed for FFPE tissue specimens, this sample prep method has been used in several microbiome studies to date. Therefore, the microbiome research field is in dire need of standardised procedures for the processing of these samples.

This study provides foundational evidence of treatments that can aid the development of such methods: (1) For bacterial lysis, treatment with bacteriolytic enzymes, such as Metapolyzyme, can improve the crosstaxa representation while not imposing risks for DNA fragmentation that bead beating would. (2) The large fraction of host DNA background could be reduced using mammalian cell-selective permeabilisation agents compatible with fixed dead cells. Here, Saponin proved effective when used in combination with a DNAse. (3) Incorporating procedures that alleviate the severity of DNA template degradation can improve DNA fragment length and sequencing quality. A sample prep method that incorporates such treatments can render a higher quality of DNA, more compatible for sequencing studies, and results that are less influenced by bias, thus improving the reliability of the results. 
An unexpected finding was a higher than expected recovery of FFPE Bifidobacterium in samples processed without undergoing bacterial lysis. The opposite was found for Staphylococcus. This persisted across all experiments and in multiple Protoblock batches $(n>30)$. This reinforces the need to thoroughly study the effect of FFPE on bacteria prior to any microbiome analysis of FFPE specimens. Principally, a thorough investigation on the effect of FFPE in bacterial membrane/cell walls should be conducted, and also the bacterial DNA itself.

Finally, contamination is a considerable threat to the accuracy of sequence-based analysis of low biomass samples such as FFPE specimens. Steps in the processing of FFPE samples require the use of solutions that are difficult to keep sterile, and contamination from these sources could easily obscure the true results in cases of low microbial load. Use of a contamination control system, such as the that proposed here: combination of an empty (agar only) and a bacteria-loaded Protoblock along with a sample of the paraffin wax used for embedding, can inform on the most common contaminants and the level of contamination introduced by any processing of FFPE samples required, in advance of a sequencing study to assess their potential influence on the studies and address their bioinformatic or biological removal. As mentioned earlier, the Protoblock contained both a known bacterial community and a comparatively high level of bacterial biomass, and therefore, the effect of contamination was negligible. However, as neither of these features are typical of clinical FFPE samples, researchers should be mindful of the susceptibility of these samples to environmental contamination.

Given the wide availability of FFPE specimens, these represent a huge potential as source material for microbiome research, especially for rare or difficult to attain samples. However, results shown in this study clearly indicate that performing microbiome studies on FFPE material has severe limitations that should not be taken lightly. For these samples to become accessible for microbiome research, dedicated workflows for this sample type must be developed and optimised. These must include sample prep methods, quality control system and a contamination control system. Only after such systems are in place can the microbiome field consider the reliable, reproducible and accurate microbiome analysis of the of FFPE specimens.

\section{Conclusion}

FFPE tissue is still far from ideal for microbiome studies. However, given the limited availability of rare 'fresh' samples, unlocking the potential of FFPE samples for microbiome analysis could have a huge effect on the field. For this to be a reality, a robust quality control system, including standards, needs to be developed. While
FFPE microbiome research is still in dire need of optimisation, the Protoblock is well placed for use in optimisation of methods in order to move the field forward.

\section{Methods \\ Preparation of Protoblocks \\ Moulds}

Moulds used to make cylinder-shaped disks were made from a $54 \times 11 \mathrm{~mm}$ adapter tube with a flat base (SARS TEDT, Cat No. 55.1570).

\section{Cell culture}

Mus musculus mammary gland cancer cells (4T1) were grown at $37^{\circ} \mathrm{C} 5 \% \mathrm{CO}_{2}$, in RPMI-1640 (Sigma-Aldrich) media supplemented with 10\% FBS (Sigma-Aldrich), $100 \mathrm{U} / \mathrm{mL}$ penicillin and $100 \mu \mathrm{g} / \mathrm{mL}$ of streptomycin (ThermoFisher), and counted with a NucleoCounter ${ }^{\circ}$ $\mathrm{NC}-100^{\mathrm{ma}}$ (ChemoMetect, Copenhagen).

\section{Bacterial growth conditions}

E. coli K12 MG1655 or E. coli Nissle 1917 carrying a P16Lux plasmid [50] were grown aerobically at $37^{\circ} \mathrm{C}$ in Luria-Bertani (LB) medium with $300 \mu \mathrm{g} / \mathrm{ml}$ Erythromycin (Sigma-Aldrich). Staphylococcus aureus Newman (ATCC 25904) was grown aerobically at $37^{\circ} \mathrm{C}$ in ToddHewitt broth (Sigma-Aldrich). Bifidobacterium longum 35624 was grown anaerobically at $37^{\circ} \mathrm{C}$ for $24 \mathrm{~h}$ in MRS medium (Sigma-Aldrich). Lactobacillus amylophilus $\left(\right.$ ATCC $\left.^{\circ} 49845^{\mathrm{Tn}}\right)$ was grown in MRS medium (Sigma-Aldrich) at $30{ }^{\circ} \mathrm{C}$ in $5 \% \mathrm{CO} 2$ for $24 \mathrm{~h}$. Bacteroides thetaiotaomicron $\left(\mathrm{ATCC}^{\circ} 29741^{\mathrm{mm}}\right.$ ) was grown anaerobically at $37^{\circ} \mathrm{C}$ for $24 \mathrm{~h}$ in FAB medium (NEOGEN, Lancashire, UK). Bacterial cultures were harvested by centrifugation and suspended in PBS. A $1 \mathrm{ml}$ aliquot of the suspension was used for to count colony-forming units (CFU) by retrospective plating. The rest was resuspended in Neutral Buffered Formalin and left to fix for $18 \mathrm{~h}$ at room temperature (RT).

\section{Counting fixed bacterial cells}

The cell suspension was counted using a bacterial counting kit for flow cytometry (Invitrogen). In brief, a 10\% aliquot from the bacterial suspension was serially diluted to $1 \times 10^{6}$ cells in $989 \mu$ l of $\mathrm{NaCl}$. Bacterial cells were stained with $1 \mu \mathrm{l}$ of SytoBC, and $10 \mu \mathrm{l}\left(1 \times 10^{6}\right)$ of counting beads was added to the suspension. Cells were counted in an LSR II Flow Cytometer (BD Biosciences). The acquisition trigger was set to side scatter and regulated for each bacterial strain to filter out electronic noise without missing bacterial cells. This value was approximately 800 . The volume corresponding to approximately $2 \times 10^{7} \mathrm{CFU}$ of each bacterial strain and $2.2 \times$ $10^{7} 4 \mathrm{~T} 1$ cells were mixed together. 


\section{Fixing cells in an agar matrix}

An equal volume $(270 \mu \mathrm{l})$ of sterile agar (1.5X of elution specified by the manufacturers) pre-aliquoted and kept at $56^{\circ} \mathrm{C}$ was pipetted into the cell suspension and thoroughly mixed by vortexing. The mixture was pipetted into the moulds and left to solidify for $3 \mathrm{~min}$ at RT. Once solidified, the disk was placed in $5 \mathrm{ml}$ of formalin for an extra $24 \mathrm{~h}$ for 48 -h fixation blocks or immediately processed for 24-h fixation blocks.

\section{Dehydration and paraffin embedding of cell disk}

Cell disks were placed into a processing cassette and processed automatically with a LOGOS J (Milestone Medical, Bergamo). Here, they were dehydrated for $4 \mathrm{~h}$ with increasing concentrations of ethanol $\left(37^{\circ} \mathrm{C}\right)$, cleared $2 \mathrm{X}$ with xylene for $2 \mathrm{~h} 20 \mathrm{~min}$ and $2 \mathrm{X}$ with isopropanol for $1 \mathrm{~h} 40 \mathrm{~min}$ at $37^{\circ} \mathrm{C}$, and $1 \mathrm{X}$ with isopropanol for 50 min at $60^{\circ} \mathrm{C}$. Finally, the blocks were embedded in paraffin for $8 \mathrm{~h} 32 \mathrm{~min}$ at $62^{\circ} \mathrm{C}$. Once paraffinised, the Protoblocks' volume, diameter and height were measured with a calliper and by volume displacement [51]. Processed Protoblocks were placed in a $1.5 \times 1.5 \mathrm{~cm}$ embedding mould and mounted to a processing cassette. All Protoblocks used in this study were stored for no longer than 12 months prior their analysis.

\section{Confirmation of cell content by microscopy Sectioning}

The blocks were sectioned using aseptic technique, either at $4 \mu \mathrm{m}$ for imaging or at $10-20 \mu \mathrm{m}$ for DNA purification. The cell load of each slide was calculated by multiplying the total bacterial load by the volume of each slide.

\section{Immunofluorescence and histochemistry}

Cell integrity was evaluated with Gram staining (SigmaAldrich) or H\&E staining with Mayer's haematoxylin (Sigma-Aldrich). Bacterial counts were confirmed in 3 sections stained with either 1:50 $\alpha$-Escherichia coli (Abcam, 137967) or 1:400 $\alpha$-Staphylococcus aureus (Abcam, 20920), counterstained with either Alexa Fluor 488 (Jackson Immunoresearch Laboratories Inc., USA) or Alexa Fluor 555-conjugated (Abcam 150062) donkey anti-rabbit Ig. Stained sections were mounted in ProLong Gold antifade reagent with DAPI (Invitrogen, UK). Gram-stained sections were counted in a bright field using an Olympus BX51 microscope, with a $\times 100$ lens. Immunofluorescent stained slides were counted at $\times 20$ (4T1 cells) or $\times 60$ (bacteria) with a fluorescence microscope (Evos FL Auto). For each slide, at least 20 randomly selected fields of view were counted. The area of the field of view (FOV) was recorded using the microscope's software and used to calculate the volume counted.

\section{DNA analysis}

\section{DNA Purification}

For purifying DNA from Protoblocks, unless specified, $10 \times 15 \mu \mathrm{m}$ sections aseptically collected were deparaffinised with $2 \mathrm{X}$ xylene washes and processed following procedures specified in the QIAGEN FFPE DNA kit protocol (Qiagen Inc., Valencia, CA, USA). This kit does not include bead beating. Therefore, bead beating was not performed. DNA was eluted in Tris-HCL buffer and quantified with a Qubit ${ }^{\mathrm{m}}$ dsDNA HS Assay Kit (Invitrogen, USA). For non-fixed bacteria, bacterial cultures were grown to an $\mathrm{OD}_{600}$ of 1 . Two-milliliter aliquots were processed following procedures of the GenElute ${ }^{\mathrm{mt}}$ Bacterial Genomic DNA Kit Protocol with Lysozyme and Lysostaphin (Sigma) (without bead beating) and eluted in $50 \mu \mathrm{l}$ of Tris- $\mathrm{HCl}$. In all cases, DNA was stored at $-20^{\circ} \mathrm{C}$ until further analysis.

\section{Fragment analysis}

One microliter of DNA purified from FFPE blocks was analysed in an Agilent 21000 bioanalyser using a High Sensitivity DNA kit (Agilent, Cat. No. 5067-4626). For Genomic Quality Number (GQN), the threshold was set to $10,000 \mathrm{bp}$ and the ratio of DNA above this threshold measured for each sample. Average fragment lengths and \%CV from area underneath a maximum peak were also measured.

\section{Quantitative PCR ( $q P C R$ )}

For dye-based $\mathrm{qPCR}$, reactions were prepared using LUNA Universal qPCR master mix (NEB, USA) and $0.25 \mu \mathrm{M}$ of each primer (sTable 2). Multiplex qPCR reactions were prepared using LUNA Universal Probe qPCR master mix (NEB, USA) and $0.5 \mu \mathrm{M}$ of each primer (sTable 2) and $0.25 \mu \mathrm{M}$ of probe for each strain. Reactions for simultaneously quantifying three bacterial strains were set using the fluorochromes: FAM, HEX and CY3. The thermal profile included a $1 \mathrm{~min}$ at $95^{\circ} \mathrm{C}$ initial denaturation, followed by 40 cycles of denaturation at $95^{\circ} \mathrm{C} \times 10 \mathrm{~s}$, annealing for $15 \mathrm{~s}$ at the temperature specified by NEB's Ta calculator for Hot Start Taq, followed by $20-40 \mathrm{~s}$ of extension at $68^{\circ} \mathrm{C}$. For each assay, a 5-point standard curve was made from $\log _{10}$ dilutions of a gene block corresponding to speciesspecific genetic regions, using an initial concentration of $10^{6}$ copies. Primers and gene-blocks were acquired from IDT (Coralville, USA) (see sTable 2 and sMaterial 1). Efficiency between 95 and $105 \%$ and R-square values > 0.995 were deemed as acceptable. All samples were run in triplicate.

\section{qPCR melt curve analysis}

For melt curve analysis, FFPE E. coli DNA was normalised to $1 \times 10^{6}$ copies/ $\mu$ l. Reactions were prepared using 
1X NEB Luna probe qPCR mix, $1.25 \mu \mathrm{M}$ EvaGreen Dye (Biotium, CA, USA), $37.5 \mathrm{nM}$ ROX as a reference dye, $0.25 \mu \mathrm{M}$ of each primer (sTable 2) and $2.5 \mu \mathrm{l}$ of template DNA. Cycling conditions used are as described for absolute quantitation with addition of a final extension step of $2 \mathrm{~min}$ at $68^{\circ} \mathrm{C}$. This was followed by high-resolution melt analysis set to read fluorescence every $0.2^{\circ} \mathrm{C}$ with 10 s soak time from 65 to $95^{\circ} \mathrm{C}$. Values for the first derivative of the normalised fluorescence multiplied by -1 were exported and analysed in R environment, v3.4.4.

\section{$16 S$ rRNA sequencing library preparation}

Amplification of the hypervariable V3-V4 region of the 16S rRNA gene (see sTable 2) was performed in $50 \mu \mathrm{l}$ reactions, containing $1 \mathrm{X}$ NEBNext High Fidelity $2 \mathrm{X}$ PCR Master Mix (NEB, USA), $0.5 \mu \mathrm{M}$ of each primer, $8 \mu \mathrm{l}$ template $(5-15 \mathrm{ng} / \mu \mathrm{l})$ and $12 \mu \mathrm{l}$ nuclease-free water. The thermal profile included an initial $98^{\circ} \mathrm{C} \times 30 \mathrm{~s}$ denaturation, followed by 25 cycles of denaturation at $98^{\circ} \mathrm{C} \times$ $10 \mathrm{~s}$, annealing at $55^{\circ} \mathrm{C} \times 30 \mathrm{~s}$ and extension at $72^{\circ} \mathrm{C} \times$ $30 \mathrm{~s}$ and a final extension at $72^{\circ} \mathrm{C} \times 5 \mathrm{~min}$. Amplification was confirmed by running $5 \mu \mathrm{l}$ of PCR product on a $2 \%$ agarose gel. Hereafter, procedures were performed as per the Illumina 16S Metagenomic Sequencing Protocol (Illumina, CA, USA). PCR products were cleaned, and sequencing libraries were prepared using the Nextera XT Index Kit (Illumina). Libraries were cleaned and quantified using a Qubit fluorometer (Invitrogen) using the 'High Sensitivity' assay. Further processing was performed by GENEWIZ (Leipzig, Germany) where samples underwent a 300-bp paired-end run on the Illumina MiSeq platform.

\section{Negative controls}

(i) Processing control: sterile agar was exposed to the complete FFPE processing workflow. (ii) Wax control: wax was taken from the edges of an FFPE block. (iii) Sample prep control: this was included by running an empty sample prep reaction. (iv) PCR control: a $16 \mathrm{~S}$ PCR reaction was loaded with microbial DNA free water.

\section{WGS sequencing library preparation}

For NF controls, DNA from bacterial cultures of Escherichia coli MG1655 and S. aureus Newman were grown as per the 'Bacterial growth conditions' section to and $\mathrm{OD}_{600}$ of 1 , and their genomic DNA was purified using the GenElute ${ }^{\mathrm{Tm}}$ Bacterial Genomic DNA Kit Protocol with Lysozyme and Lysostaphin (Sigma). For FFPE bacteria, DNA from Protoblocks containing either strain was purified using the QIAGEN FFPE kit. In all cases, DNA was eluted in $50 \mu \mathrm{l}$ of Tris- $\mathrm{HCl}$. Total purified DNA was sent to GENEWIZ (Leipzig, Germany) where
WGS was performed using $2 \times 150$ bp chemistry on an Illumina HiSeq.

\section{Murine models}

Animals, mammalian cell culture and tumour induction

Murine experiments were approved by the Health Products Regulatory Authority (Dublin, Ireland) and the Animal Experimentation Ethics Committee of University College Cork (Cork, Ireland). RENCA cells were grown in RPMI media (Sigma) + 10\% FBS (Sigma) and counted with a NucleoCounter (ChemoMetec). Tumours were induced in 8-week-old BALB/c mice by subcutaneous injection of $1 \times 10^{6}$ cells suspended in $200 \mu \mathrm{l}$ serum-free RPMI media. Tumours were measured daily with a Vernier calliper, and their volume was calculated by measuring their longest diameter, and at the diameter perpendicular to this.

\section{Bacterial preparation and administration}

Bacteria were prepared for administration once murine tumours were approximately $5 \times 5 \mathrm{~mm}$ in diameter. $E$. coli Nissle 1917 was grown to an $\mathrm{OD}_{600}$ of 0.8 in $\mathrm{LB}$ media, with $300 \mu \mathrm{g} / \mathrm{ml}$ erythromycin, harvested by centrifugation and washed $3 \mathrm{X}$ with PBS. Bifidobacterium breve UCC2003 was grown anaerobically for $24 \mathrm{~h}$ in Man, Rogosa and Sharpe (MRS) media (Oxoid), + 0.05\% L-cysteine hydrochloride (Sigma), and harvested and washed $3 \mathrm{X}$ with $\mathrm{PBS}+0.05 \% \mathrm{~L}$-cysteine. Both bacterial strains were serially diluted to $1 \times 10^{7} \mathrm{CFU} / \mathrm{ml}$. Tumour-bearing mice were administered $100 \mu \mathrm{l}$ of either bacterial suspension or PBS (negative control) via lateral tail vein injection, as per [50]. Bacterial counts were confirmed by retrospectively plating in LB agar supplemented with $300 \mu \mathrm{g} / \mathrm{ml}$ erythromycin (E. coli) or RCA supplemented with $50 \mathrm{mg} / \mathrm{L}$ mupirocin (B. breve).

\section{Bacterial recovery from mice}

Mice were culled 7-11 days after bacterial administration. Tumours were aseptically excised and halved. One half was placed in $10 \%$ buffered formalin and fixed for $24 \mathrm{~h}$ at RT. The other half was placed in $1 \mathrm{ml}$ PBS (+ $0.05 \%$ L-cysteine for B. breve) and homogenised using a $70-\mu \mathrm{m}$ nylon cell strainer (Corning). Cell strainers were washed with $1 \mathrm{ml}$ PBS. Homogenised tumours were serially diluted with PBS and plated for retrospective counting as per [52].

\section{Formalin-fixed tissue processing}

Formalin-fixed murine tissues were placed between two biopsy pads (Kaltek) in a histology cassette and processed using a LOGOS J Hybrid Tissue Processor (Milestone) and paraffin embedded as per the 'Dehydration and paraffin embedding of cell disk' section. 


\section{DNA extraction and analysis of FFPE tissue}

The $8 \times 10 \mu \mathrm{m}$ sections were processed for each specimen. Samples were subsequently processed with a QIAamp DNA FFPE Tissue kit (Qiagen) per the standard protocol, with the following exceptions: Tissue was deparaffinised with $2 \mathrm{X}$ xylene washes and the incubation with Buffer ATL and Proteinase $\mathrm{K}$ was performed for 1 h 45 min. DNA was eluted in $35 \mu \mathrm{l}$ Buffer ATE. Quantitative PCR reactions were set up as per the 'Quantitative PCR (qPCR)' section, using primers and probes specified in sTable 2.

\section{Bioinformatics and statistical analysis Statistical analysis}

All statistical analyses were performed in the $\mathrm{R}$ environment, v3.4.4, using methods stated in the figure legends.

\section{S rRNA gene sequence analysis}

The quality of the paired-end sequence data was initially visualised using FastQC v0.11.6, and then filtered and trimmed using Trimmomatic v0.36 to ensure a minimum average quality of 25 . The remaining high-quality reads were then imported into the $\mathrm{R}$ environment v3.4.4 for analysis with the DADA2 package v1.8.0. After further quality filtering, error correction and chimera removal, the raw reads generated by the sequencing process were refined into a table of Amplicon Sequence Variants (ASVs) and their distribution among the samples. As the aim was to characterise if contamination is present, rather than to remove it, negative controls were included to compare with the FFPE Protoblocks, with no further action taken. Bacterial sequence reads were classified using the Mothur classifier [53], trained on the RDP database (v11.4).

\section{Variant calling from whole genome sequence data}

Filtering: HiSeq sequence data was quality filtered. Only very high-quality bases were considered, to minimise the risk of sequencing errors causing false positive variants. Short fragments were also removed to reduce the likelihood of spurious alignments of regions from contaminant bacterial genomes. Trimmomatic was used to remove all reads shorter than $50 \mathrm{bp}$ in length and to trim reads when the average per base quality in a sliding window of size 4 dropped below 30 .

Alignment: Of the three possible Burrows-Wheeler alignment tools, the BWA-mem aligner was used as the average read length was $150 \mathrm{bp}$, and BWA-mem is recommended when reads are over $70 \mathrm{bp}$ in length as per the manual reference pages [54]. Default settings were used with the exception of allowing alignments with a minimum score of 0 , rather than the default 30 as we were unsure of the extent of DNA damage-induced sequence alterations. Given the stringent parameters used for read length and quality filtering, relaxing the minimum alignment score gave the best possible chance of variant detection. Samples were aligned to the original reference genome, E. coli MG1655.

Variant calling: Variant calling was done with BCF tools, using the BCF call function. The variants were then filtered using the norm and filter functions within BCF tools. Filtering was performed to remove variants when the read depth was below 10, the quality was below 40, or when the variant identified was not supported by both the forward and reverse read of a read pair.

\section{Supplementary information}

Supplementary information accompanies this paper at https://doi.org/10. 1186/s40168-020-00901-1.

\section{Additional file 1.}

\section{Abbreviations}

BSA: Bovine serum albuminCFUColony-forming unitsFFPEFormalin-fixed paraffin-embeddedH\&EHaematoxylin \& eosinHRMHigh-resolution melt analysisLBLuria-BertaniNFNon-fixedNGSNext-generation sequencingPBSPhosphate buffer salinePCRPolymerase chain reactionqPCRReal-time PCRRTRoom temperatureTmMelting temperatureWGSWhole genome sequencing

\section{Acknowledgements}

We wish to thank the support of Juliet Barry (CancerResearch@UCC) for her valuable advice and for providing technical training to authors throughout the project.

\section{Authors' contributions}

YFB and MT conceived and designed the study. YFB executed the laboratory work. GH performed the animal studies. SPW and YFB performed the data analyses. YFB, SPW, MC and MT interpreted the results and wrote the manuscript. The authors read and approved the final manuscript.

\section{Funding}

The authors wish to acknowledge support relevant to this manuscript from the Irish Research Council (GOIPG/2016/475), Science Foundation Ireland (12/ RC/2273; 15/CDA/3630), the Health Research Board (MRCG2016-25) and Breakthrough Cancer Research.

\section{Availability of data and materials}

Both 165 and WGS sequence data will be made available on the SRA upon acceptance of the manuscript. Additional data sets and material is available upon reviewers' request.

Ethics approval and consent to participate Not applicable.

\section{Consent for publication}

Not applicable.

\section{Competing interests}

The authors declare that they have no competing interests.

\section{Author details}

'CancerResearch@UCC, University College Cork, Cork, Ireland. ${ }^{2}$ SynBioCentre, University College Cork, Cork, Ireland. ${ }^{3}$ APC Microbiome Ireland, University College Cork, Cork, Ireland. ${ }^{4}$ School of Microbiology, University College Cork, Cork, Ireland. 
Received: 13 March 2020 Accepted: 24 July 2020

Published online: 22 August 2020

\section{References}

1. Hall N. Advanced sequencing technologies and their wider impact in microbiology. J Exp Biol. 2007;210(9):1518-25.

2. Forbes JD, et al. Metagenomics: The next culture-independent game changer. Front Microbiol. 2017:8:1069.

3. Knight $R$, et al. Best practices for analysing microbiomes. Nat Rev Microbiol. 2018;16(7):410-22.

4. Castillo DJ, et al. The healthy human blood microbiome: fact or fiction. Front Cell Infect Microbiol. 2019;9:148.

5. Stinson LF, et al. The not-so-sterile womb: evidence that the human fetus is exposed to bacteria prior to birth. Front Microbiol. 2019;10:1124.

6. Ozkan J, et al. Identification and visualization of a distinct microbiome in ocular surface conjunctival tissue. Invest Ophthalmol Vis Sci. 2018;59(10):4268-76.

7. Zhou B, et al. The biodiversity composition of microbiome in ovarian carcinoma patients. Sci Rep. 2019;9(1):1691.

8. Chen J, et al. The microbiome and breast cancer: a review. Breast Cancer Res Treat. 2019.

9. Beck JM, Young VB, Huffnagle GB. The microbiome of the lung. Transl Res. 2012;160(4):258-66.

10. Huffnagle GB, Dickson RP, Lukacs NW. The respiratory tract microbiome and lung inflammation: a two-way street. Mucosal Immunol. 2017;10(2):299-306.

11. Marsh RL, et al. The microbiota in bronchoalveolar lavage from young children with chronic lung disease includes taxa present in both the oropharynx and nasopharynx. Microbiome. 2016;4(1):37.

12. Emery $D C$, et al. $16 \mathrm{~S}$ rRNA next generation sequencing analysis shows bacteria in Alzheimer's post-mortem brain. Front Aging Neurosci. 2017;9:195.

13. Stewart CJ, et al. Using formalin fixed paraffin embedded tissue to characterize the preterm gut microbiota in necrotising enterocolitis and spontaneous isolated perforation using marginal and diseased tissue. BMC Microbiol. 2019;19(1):52.

14. Hart JD, et al. $16 \mathrm{~S}$ rRNA sequencing in molecular microbiological diagnosis of bacterial infections in the autopsy setting. Pathology. 2014;46:S113.

15. Racsa LD, et al. Identification of bacterial pathogens from formalin-fixed, paraffin-embedded tissues by using 165 sequencing: retrospective correlation of results to clinicians' responses. Hum Pathol. 2017:59:132-8.

16. Banerjee $\mathrm{S}$, et al. Distinct microbial signatures associated with different breast cancer types. Front Microbiol. 2018;9:951.

17. Baldwin DA, et al. Metagenomic assay for identification of microbial pathogens in tumor tissues. mBio. 2014;5(5):e01714.

18. Riquelme $\mathrm{E}$, et al. Tumor microbiome diversity and composition influence pancreatic cancer outcomes. Cell. 2019;178(4):795-806.e12.

19. Xuan C, et al. Microbial dysbiosis is associated with human breast cancer. PLoS One. 2014;9(1):e83744.

20. Gaffney EF, et al. Factors that drive the increasing use of FFPE tissue in basic and translational cancer research. Biotech Histochem. 2018:93(5):373-86.

21. van Beers EH, et al. A multiplex PCR predictor for aCGH success of FFPE samples. Br J Cancer. 2006;94(2):333-7.

22. Blow N. Tissue issues. Nature. 2007;448(7156):959-60.

23. Kerick $M$, et al. Targeted high throughput sequencing in clinical cancer Settings: formaldehyde fixed-paraffin embedded (FFPE) tumor tissues, input amount and tumor heterogeneity. BMC Med Genomics. 2011;4(1):68.

24. Hedegaard, J., et al., Next-generation sequencing of RNA and DNA isolated from paired fresh-frozen and formalin-fixed paraffin-embedded samples of human cancer and normal tissue. PloS one, 2014. 9(5): p. e98187-e98187.

25. McDonough, S.J., et al., Use of FFPE-derived DNA in next generation sequencing: DNA extraction methods. PloS one, 2019. 14(4): p. e0211400e0211400.

26. Kresse $\mathrm{SH}$, et al. Evaluation of commercial DNA and RNA extraction methods for high-throughput sequencing of FFPE samples. PLoS One. 2018; 13(5):e0197456.

27. Siebolts $U$, et al. Tissues from routine pathology archives are suitable for microRNA analyses by quantitative PCR. J Clin Pathol. 2009;62(1):84-8.

28. Fanelli $\mathrm{M}$, et al. Chromatin immunoprecipitation and high-throughput sequencing from paraffin-embedded pathology tissue. Nat Protoc. 2011; 6(12):1905-19.

29. Srinivasan M, Sedmak D, Jewell S. Effect of fixatives and tissue processing on the content and integrity of nucleic acids. Am J Pathol. 2002;161(6): 1961-71.
30. Vitosevic $\mathrm{K}$, et al. Effect of formalin fixation on pcr amplification of DNA isolated from healthy autopsy tissues. Acta Histochem. 2018;120(8):780-8.

31. Hykin, S.M., K. Bi, and J.A. McGuire, Fixing formalin: a method to recover genomic-scale DNA sequence data from formalin-fixed museum specimens using high-throughput sequencing. PloS one, 2015. 10(10): p. e0141579e0141579.

32. Feehery, G.R., et al., A method for selectively enriching microbial DNA from contaminating vertebrate host DNA. PloS one, 2013. 8(10): p. e76096e76096.

33. Do H, Dobrovic A. Sequence artifacts in DNA from formalin-fixed tissues: causes and strategies for minimization. Clin Chem. 2015;61(1):64-71.

34. Ruiz $L$, et al. How do bifidobacteria counteract environmental challenges? Mechanisms involved and physiological consequences. Genes Nutr. 2011; 6(3):307-18.

35. Einaga $\mathrm{N}$, et al. Assessment of the quality of DNA from various formalinfixed paraffin-embedded (FFPE) tissues and the use of this DNA for nextgeneration sequencing (NGS) with no artifactual mutation. PLoS One. 2017; 12(5):e0176280

36. Bailey, S.T., et al., High-quality wse sequencing of FFPE samples J. Clin. Oncol, 2018. 36(15_suppl): p. e13500-e13500.

37. Bettoni F, et al. A straightforward assay to evaluate DNA integrity and optimize next-generation sequencing for clinical diagnosis in oncology. Exp Mol Pathol. 2017;103(3):294-9.

38. Costea Pl, et al. Enterotypes in the landscape of gut microbial community composition. Nat Microbiol. 2018;3(1):8-16.

39. Proctor $\mathrm{L}$. Priorities for the next 10 years of human microbiome research. Nature. 2019;569(7758):623-5.

40. Costea PI, et al. Towards standards for human fecal sample processing in metagenomic studies. Nat Biotechnol. 2017;35:1069.

41. Katsnelson A. Standards seekers put the human microbiome in their sights. ACS Cent Sci. 2019;5(6):929-32.

42. Hasan MR, et al. Depletion of human DNA in spiked clinical specimens for improvement of sensitivity of pathogen detection by next-generation sequencing. J Clin Microbiol. 2016;54(4):919.

43. Illumina, I, Evaluating DNA Quality from FFPE Samples, in Technical Note: Library Preparation. 2016, Illumina, Inc. https://www.illumina.com/content/ dam/illumina-marketing/documents/products/technotes/truseq-exome-ffpetech-note-770-2015-035.pdf.

44. Lenze D, Müller H, Hummel M. Considerations for the use of formalin-fixed and paraffin-embedded tissue specimens for clonality analysis. J Hematopathol. 2012;5:27-34. https://doi.org/10.1007/s12308-012-0138-8.

45. Dietrich D, Uhl B, Sailer $V$, et al. Improved PCR performance using template DNA from formalin-fixed and paraffin-embedded tissues by overcoming PCR inhibition. PLoS One. 2013;8(10):e77771. https://doi.org/10.1371/journal. pone.0077771.

46. Robbe $P$, et al. Clinical whole-genome sequencing from routine formalinfixed, paraffin-embedded specimens: pilot study for the 100,000 Genomes Project. Genet Med. 2018;20(10):1196-205.

47. Choo JM, Leong LEX, Rogers GB. Sample storage conditions significantly influence faecal microbiome profiles. Sci Rep. 2015;5:16350.

48. Goldberg B, et al. Making the leap from research laboratory to clinic: challenges and opportunities for next-generation sequencing in infectious disease diagnostics. mBio. 2015;6(6):e01888-15.

49. Hornung BVH, Zwittink RD, Kuijper EJ. Issues and current standards of controls in microbiome research. FEMS Microbiol Ecol. 2019:95(5).

50. Cronin $\mathrm{M}$, et al. High resolution in vivo bioluminescent imaging for the study of bacterial tumour targeting. PLoS One. 2012;7(1):e30940.

51. Hughes S, Lau J. A technique for fast and accurate measurement of hand volumes using Archimedes' principle. Australasian Physics \& Engineering Sciences in Medicine. 2008;31(1):56.

52. Cronin $\mathrm{M}$, et al. Orally administered bifidobacteria as vehicles for delivery of agents to systemic tumors. Mol Ther. 2010;18(7):1397-407.

53. Schloss PD, et al. Introducing mothur: open-source, platform-independent, community-supported software for describing and comparing microbial communities. Appl Environ Microbiol. 2009;75(23):7537-41.

54. Li, H. bwa - Burrows-Wheeler Alignment Tool. 2013; Available from: http:// bio-bwa.sourceforge.net/.

\section{Publisher's Note}

Springer Nature remains neutral with regard to jurisdictional claims in published maps and institutional affiliations. 